\title{
Photon Irradiation Effects on the Enduray Vision System for Nuclear Inspections
}

Experimental Operations and Facilities Division 


\begin{abstract}
About Argonne National Laboratory
Argonne is a U.S. Department of Energy laboratory managed by UChicago Argonne, LLC

under contract DE-AC02-06CH11357. The Laboratory's main facility is outside Chicago,

at 9700 South Cass Avenue, Lemont, Illinois 60439. For information about Argonne

and its pioneering science and technology programs, see www.anl.gov.
\end{abstract}

\title{
DOCUMENT AVAILABILITY
}

Online Access: U.S. Department of Energy (DOE) reports produced after 1991 and a growing number of pre-1991 documents are available free at OSTI.GOV (http://www.osti.gov/),

a service of the US Dept. of Energy's Office of Scientific and Technical Information.

Reports not in digital format may be purchased by the public from the National Technical Information Service (NTIS):

U.S. Department of Commerce

National Technical Information Service

5301 Shawnee Road

Alexandria, VA 22312

unw.ntis.gov

Phone: (800) 553-NTIS (6847) or (703) 605-6000

Fax: (703) 605-6900

Email: orders@ntis.gov

Reports not in digital format are available to DOE and DOE contractors from the Office of Scientific and Technical Information (OSTI):

U.S. Department of Energy

Office of Scientific and Technical Information

P.O. Box 62

Oak Ridge, TN 37831-0062

unw.osti.gov

Phone: (865) 576-8401

Fax: (865) 576-5728

Email: reports@osti.gov

\section{Disclaimer}

This report was prepared as an account of work sponsored by an agency of the United States Government. Neither the United States Government nor any agency thereof, nor UChicago Argonne, LLC, nor any of their employees or officers, makes any warranty, express or implied, or assumes any legal liability or responsibility for the accuracy, completeness, or usefulness of any information, apparatus, product, or process disclosed, or represents that its use would not infringe privately owned rights. Reference herein to any specific commercial product, process, or service by trade name, trademark, manufacturer, or otherwise, does not necessarily constitute or imply its endorsement, recommendation, or favoring by the United States Government or any agency thereof. The views and opinions of document authors expressed herein do not necessarily state or reflect those of the United States Government or any agency thereof, Argonne National Laboratory, or UChicago Argonne, LLC. 
ANL-20/09

\section{Photon Irradiation Effects on the Enduray Vision System for Nuclear Inspections}

by

Kevin Quigley1, Kenneth Wesolowski ${ }^{1}$, James Bailey', Sergey Chemerisov'1, Tony Moretti ${ }^{2}$, Joseph Salzberg ${ }^{2}$, David Jenkins ${ }^{2}$, and Alan Sugg ${ }^{2}$

${ }^{1}$ Experimental Operations and Facilities Division, Argonne National Laboratory

${ }^{2}$ Vega Wave Systems, Inc

January 2020 



\section{CONTENTS}

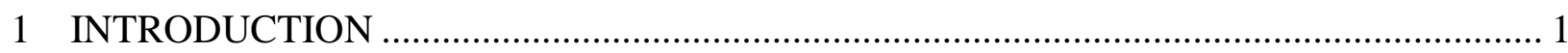

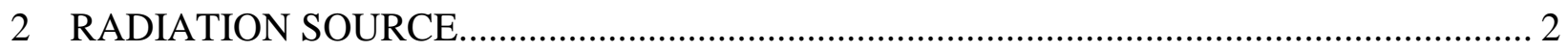

2.1 Description of Van de Graaff Accelerator Facility ................................................. 2

2.2 X-ray Converter Design ....................................................................................... 2

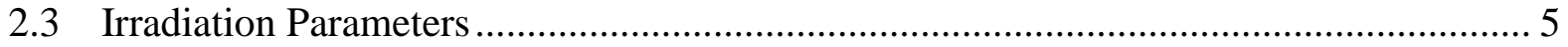

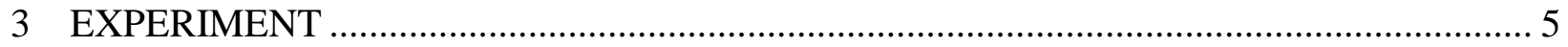

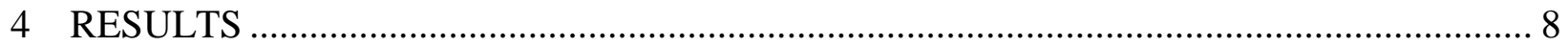

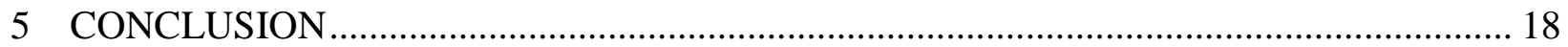

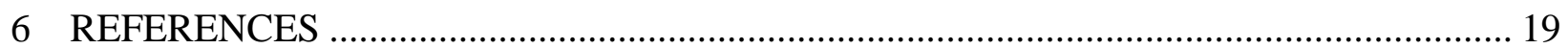

\section{FIGURES}

1 Theoretical spectrum of Bremsstrahlung photons for 3-MeV beam impinging on

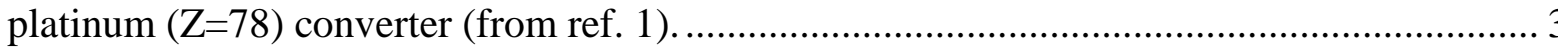

2 Drawing of the $\mathrm{x}$-ray converter assembly. The platinum converter plate is sandwiched

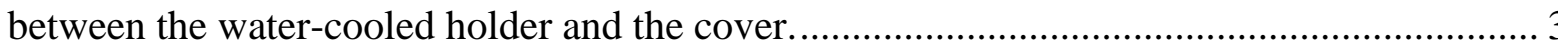

3 Results of the computer simulation ${ }^{2}$ of heat deposited in the platinum converter plate, cooled through mechanical contact at the edge. The temperature of the water-cooled copper holder is $20^{\circ} \mathrm{C}$.

4 Experimental setup, side view. The camera head and video target (a radiationhardened electro-mechanical clock) were placed in an enclosed aluminum box that was fixed in front of the Van de Graaff radiation port. Nitrogen flowed in from the

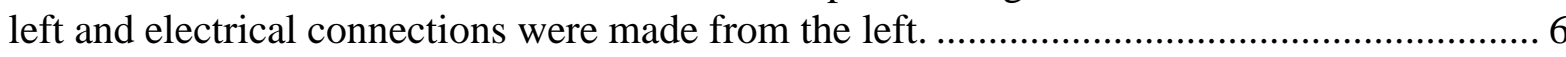

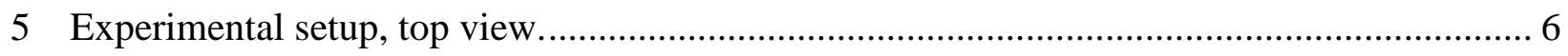

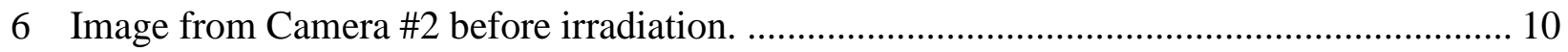

7 Image from Camera \#2 after completion of irradiation testing (760-kGy passive

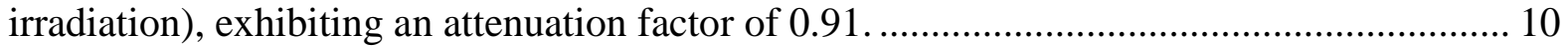

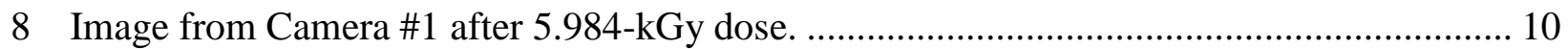

9 Screen shot of the camera control software before irradiation. Below the image in the upper left is a cross section of the intensity across the clock face. The sample area window where the noise calculation was made is shown above the 12 o'clock position. This sample window eliminated the "noise" effects of the moving clock hands. 


\section{FIGURES (CONT.)}

10 Screen shot of the camera control software for camera irradiated at a rate of $10 \mathrm{kGy} / \mathrm{hr}$ with a total dose of $425 \mathrm{kGy}$. Note that the image frame shows no observable effect of the radiation, which is effectively at 10X the maximum dose rate of a commercial application.

11 The mean gray level and mean noise of the window shown in the clock face for the first 15 minutes of irradiation at $1 \mathrm{kGy} / \mathrm{hr}$. The images are taken at 30 frames per second.

12 Full-frame noise listed in Table 3 as a function of cumulative dose. Note: full-frame noise contains accumulating errors due to the movement of the clock hands, and is therefore less representative of the actual noise than the window noise data......

13 Full-frame noise listed in Table 3 as a function of dose rate. .......................................... 14

14 Image width vs. cumulative irradiation dose of Camera \#3.

15 Image width for Camera \#4 vs. cumulative irradiation dose. This plot does not show the effect seen in Camera \#3 (Figure 14), and the preliminary attribution of the radiation effect is ionized contaminants, which were eliminated or reduced in Camera \#4......

16 Window noise first hour of irradiation at a dose rate $2.0 \mathrm{KGy} / \mathrm{h}$ and first hour 10 $\mathrm{KGy} / \mathrm{h}$ after $425 \mathrm{KGy}$ total dose as a function of total accumulated dose for Camera \#4

17 Window noise (first hour) of irradiation at a dose rate $2.0 \mathrm{KGy} / \mathrm{h}$ and window noise (first hour) at $10 \mathrm{KGy} / \mathrm{h}$ after $425 \mathrm{KGy}$ total dose as a function of dose rate for Camera \#4.

\section{TABLES}

1 Van de Graaff current calculations from irradiation dose rates ${ }^{*}$.......................................... 5

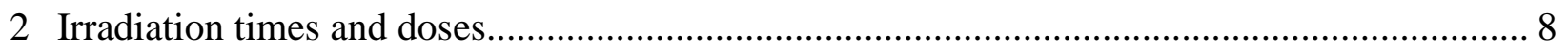

3 Average gray levels and average noise levels for the full image and the window subsample shown in Figure 12 and Figure 13. 


\section{INTRODUCTION}

Video cameras with greater radiation hardening are needed for the operation and remote handling of equipment in nuclear reactor inspection and refueling applications. Vega Wave Systems has developed a radiation-hardened vision system for nuclear energy applications. The program described in this report provided radiation-hardness testing of this vision system using the Argonne Low-Energy Accelerator Facility (LEAF).

This report presents the results of irradiation tests performed on several of Vega Wave System's cameras at dose rates ranging from $1 \mathrm{kGy} / \mathrm{hr}$ up to $10 \mathrm{kGy} / \mathrm{hr}$ and up to total doses of $>500 \mathrm{kGy}$.

The results were excellent, providing proof of the camera system's immunity to radiation effects at all levels tested.

The Problem: The nuclear energy industry needs vision systems with higher image quality and greater radiation-hardening for refueling and inspection operations that are required every 12 to 18 months for all operating commercial reactors. During refueling operations, the serial numbers of fuel assemblies need to be visually verified in a challenging high-radiation environment with dose rates on the order of $1 \mathrm{kGy} / \mathrm{hr}$ at the top of the core (approximately 10 days after shutdown). The problems encountered during refueling operations include difficulties in reading the serial numbers of fuel assemblies due to contaminants and thermal currents in the pool, and the necessity of "working blind" when attaching the grappling assembly to the top of the fuel assembly. Current cameras are based upon the Vidicon tube, a 1960s television camera technology. In order to make the tubes radiation-hard, the cameras must be heavily shielded (with $80 \mathrm{lb}$ of lead) and operated a minimum of two meters from the fuel assemblies. If the cameras are brought closer to the fuel, they will burn out in approximately $20 \mathrm{~min}$, requiring an expensive and time-consuming replacement [source: interviews with engineers at Exelon's nuclear plants at Braidwood, Byron, and Sizewell B].

The Solution: Vega Wave Systems, Inc., has developed and built a radiation-hardened vision system that overcomes the problems of current commercially available radiation-hardened cameras. The Enduray Vision System consists of a highly radiation-tolerant video camera, control electronics, a PC controller, and advanced image acquisition and processing software.

Crucial Assistance from the Department of Energy: Vega Wave Systems, Inc., needs to verify the radiation tolerance of the Enduray Vision System. This verification requires radiation levels that are much higher than normally produced by commercial or medical sources. The source for initial testing would ideally produce a high dose rate, be a pure photon source to prevent activation of the system and thus allow for easy access and close visual inspection and evaluation of radiation effects, and allow easy setup and operation of the vision system. Specifically, for ideal testing of the Enduray system, the following criteria must be met:

- High maximum dose rate, equivalent to or exceeding $1 \mathrm{kGy} / \mathrm{hr}$

- Easily controllable radiation dose rate for evaluating dose rate tolerance 
- Non-activating radiation fields for early prototype evaluation and debugging

- Relevant energy spectrum

Fortunately, the Van de Graaff system at Argonne National Laboratory is ideally suited to these requirements. The system provides a $3-\mathrm{MeV}$ x-ray source that reasonably approximates the energy and spectrum of the gamma radiation expected at the top of a nuclear core 10 days after shutdown $(1 \mathrm{kGy} / \mathrm{hr})$, is easily controlled for variable tests, and of course, will not activate the parts under radiation, allowing timely and close inspection and characterization of the vision system in case of operational issues. Vega Wave searched for alternative facilities that met these requirements and was not able to locate a more suitable radiation source.

\section{RADIATION SOURCE}

\subsection{Description of Van de Graaff Accelerator Facility}

The 3-MeV Van de Graaff electron accelerator at Argonne National Laboratory is operated as a part of LEAF and managed by the Experimental Operations and Facilities Division. The 3-MeV Van de Graaff is a pulsed electron accelerator that provides a variable-energy beam over the range of $300 \mathrm{keV}$ to $3 \mathrm{MeV}$. The peak beam intensity is $3 \mathrm{~A}$, and the minimum pulse width is $5 \mathrm{~ns}$. The accelerator is capable of producing intense ionizing radiation fields.

The Van de Graaff accelerator is normally operated in the pulsed mode at repetition rates of up to $10 \mathrm{kHz}$. The pulse width is variable between $5 \mathrm{~ns}$ and $10 \mu \mathrm{s}$. The peak current is $3 \mathrm{~A}$, and the maximum average current is $100 \mu \mathrm{A}$. The Van de Graaff accelerator is also capable of generating a continuous electron beam with a maximum current of $100 \mu \mathrm{A}$. For this project, the Van de Graaff accelerator was operated in continuous-beam mode to provide a constant radiation field.

\subsection{X-ray Converter Design}

The primary particles produced by the Van de Graaff accelerator are electrons. The energy of the electron beam can be converted to photons via the Bremsstrahlung process. In this process, the electron beam impinges on high-Z material (x-ray converter) and electromagnetic radiation (photons) is produced from decelerating of electrons by an atomic nucleus.

Bremsstrahlung photons have a continuous spectrum spanning from zero to the maximum energy of the primary beam (Figure 1).

In the past, we have utilized different materials for construction of the converter. Tungsten and tantalum are the conventional choices for the converter material. Our experience demonstrated poor chemical stability of those elements at elevated temperatures and in the presence of oxygen. For this project, we designed a new converter that can withstand the high beam currents produced by the Van de Graaff accelerator. The design of the converter is shown in Figure 2. The converter mounts directly in the exit window of the accelerator. To facilitate 
good thermal contact between the platinum plate and copper holder, we added soft aluminum gaskets on both sides. Insulator (Kapton tape) was placed around the outside circumference of the window to provide electrical isolation of the converter. Electrical isolation is important because it allows us to measure current continuously during irradiation.

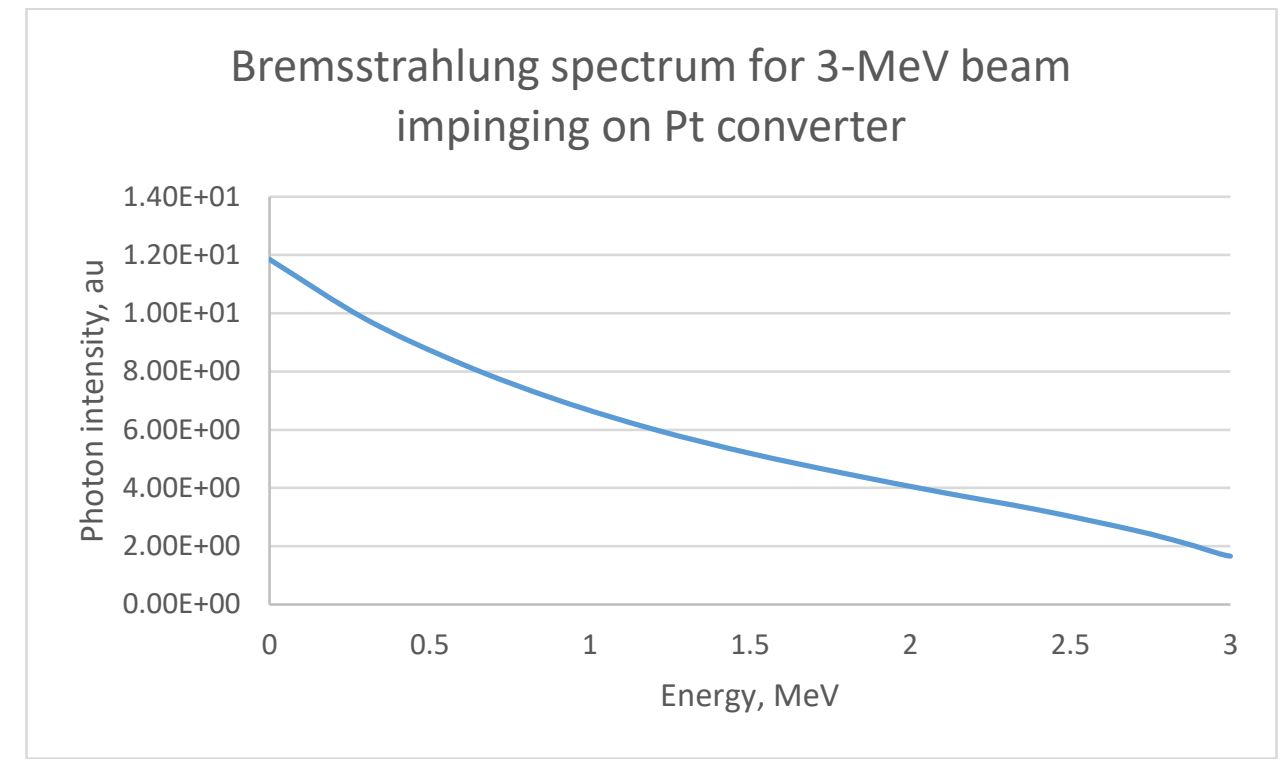

FIGURE 1 Theoretical spectrum of Bremsstrahlung photons for 3-MeV beam impinging on platinum $(Z=78)$ converter (from ref. 1$)$.

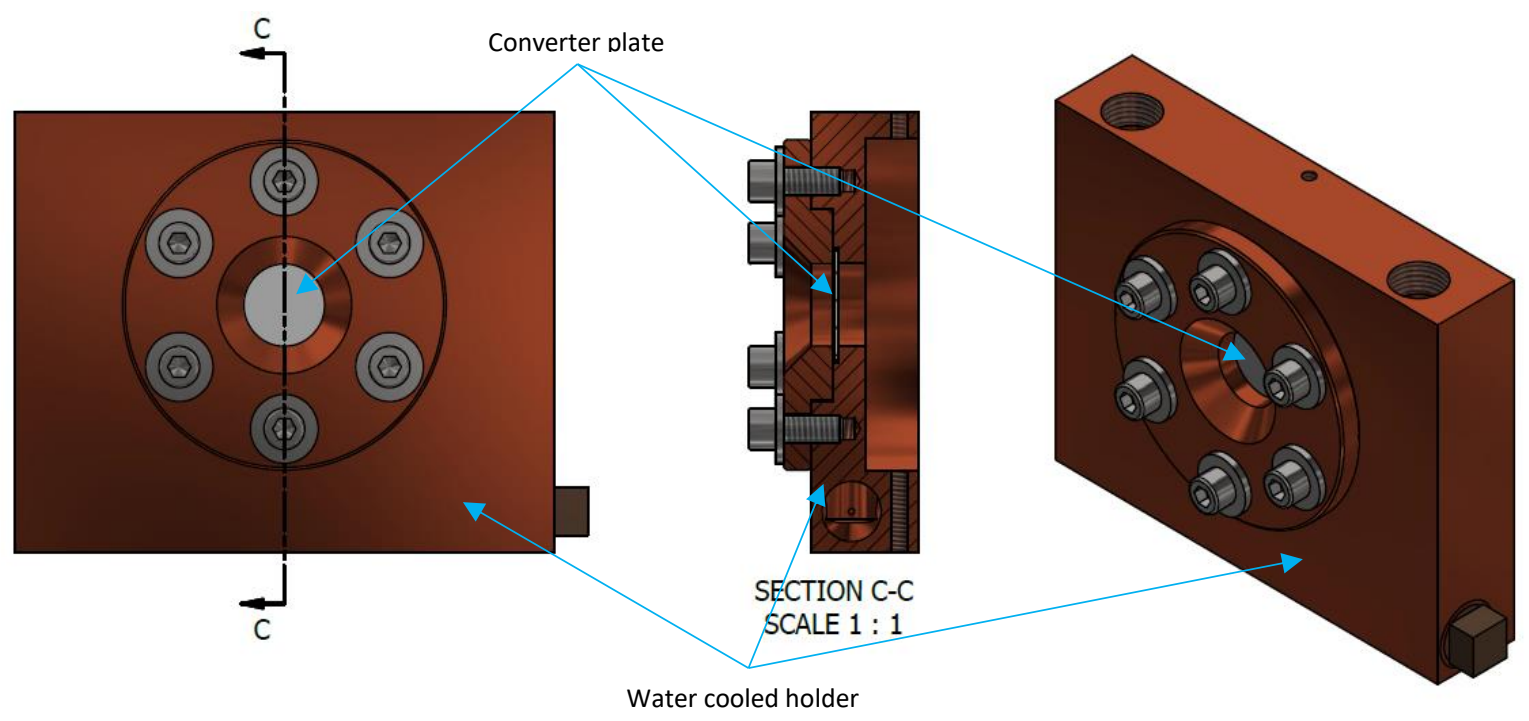

FIGURE 2 Drawing of the $x$-ray converter assembly. The platinum converter plate is sandwiched between the water-cooled holder and the cover. 
Figure 3 shows results for computer simulations ${ }^{2}$ of converter heating with the beam. Those simulations were performed for a $100-\mu \mathrm{A}$ beam at $3 \mathrm{MeV}$ with a Gaussian profile characterized by a 6-mm Full Width at Half Maximum. Calculations predict an $1180^{\circ} \mathrm{C}$ maximum temperature in the center of the platinum plate and $\sim 200^{\circ} \mathrm{C}$ at the edge of the plate. Those temperatures are acceptable for platinum that stays inert in the air.

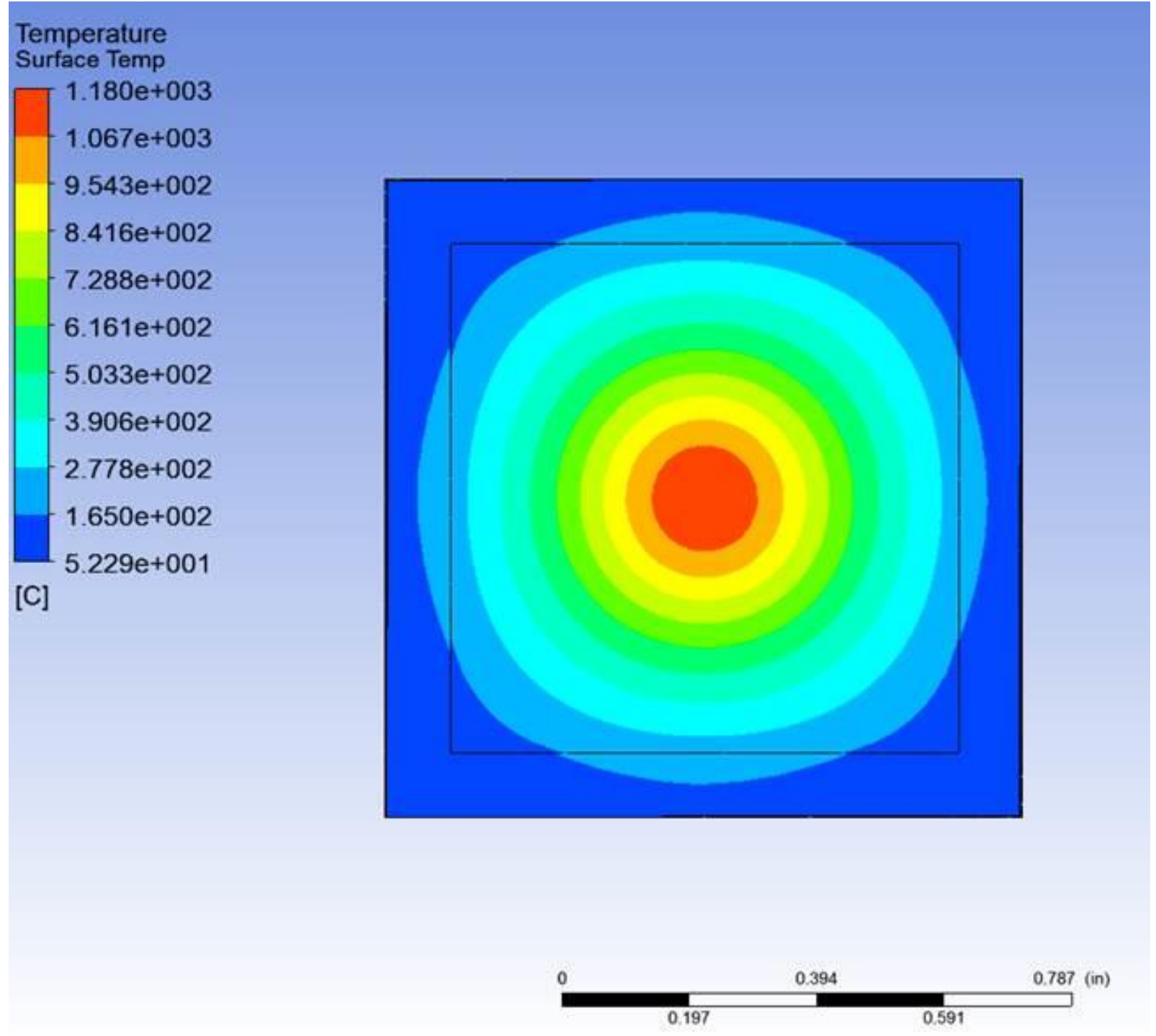

FIGURE 3 Results of the computer simulation ${ }^{2}$ of heat deposited in the platinum converter plate, cooled through mechanical contact at the edge. The temperature of the water-cooled copper holder is $20^{\circ} \mathrm{C}$. 


\subsection{Irradiation Parameters}

Irradiations were performed at $3 \mathrm{MeV}$. The cameras were positioned at a known distance from the photon converter. Initial dose rates were measured using a Radcal Model 9010 dosimeter placed at different distances from the converter. Results of the measurements are summarized in Table 1. These dose rates were used to calculate the dose during each irradiation.

Four cameras were irradiated at varying distances from the converter, ranging from 6 in. to 1 in. Distance and current were determined according to the desired dose rate. The dose rates varied from $1 \mathrm{~Gy} / \mathrm{hr}$ to $10 \mathrm{kGy} / \mathrm{hr}$. The irradiation times and dose rates used in the camera irradiations are summarized in Table 2. High-purity nitrogen was used to purge ozone from the camera during irradiation.

\section{TABLE 1 Van de Graaff current calculations from irradiation dose rates*}

\begin{tabular}{cccc}
\hline $\begin{array}{c}\text { Dose Rate } \\
(\mathrm{Gy} / \mathrm{hr})\end{array}$ & $\begin{array}{c}\text { Dose Rate } \\
(\mathrm{rad} / \mathrm{min})\end{array}$ & $\begin{array}{c}\text { Distance } \\
(\mathrm{in} .)\end{array}$ & $\begin{array}{c}\text { Van de Graaff Current } \\
(\mu \mathrm{A})\end{array}$ \\
\hline & & & \\
1,000 & 1,667 & 3.0 & 5.8 \\
2,000 & 3,333 & 3.0 & 15.7 \\
3,000 & 5,000 & 3.0 & 25.6 \\
4,000 & 8,333 & 3.0 & 45.3 \\
5,000 & 8,333 & 1.0 & 16.6 \\
7,000 & 11,667 & 1.0 & 24.9 \\
10,000 & 16,667 & 1.0 & 37.4 \\
\hline
\end{tabular}

* The values for the current were calculated from interpolation formulas: For distance $=1$ in.: $\mathrm{I}(\mu \mathrm{A})=($ Dose rate in $\mathrm{rad} / \mathrm{min}-1,661) / 401.7$

For distance $=3$ in.: $\mathrm{I}(\mu \mathrm{A})=($ Dose rate in $\mathrm{rad} / \mathrm{min}-677) / 169$

\section{EXPERIMENT}

Two of the prototype cameras were irradiated in active mode (camera operational during irradiation) and two in passive mode (camera non-operational during irradiation). In active mode, the camera was recording an image continuously with full computer control. In passive mode, the camera was placed in front of the radiation source by itself, with no connection to any external control device, and was not operational during the irradiation; the image data were captured after the irradiation session in a non-radiation environment. The setup is shown in FIGURE 4 and Figure 5. All the following steps of the irradiation procedure apply to the cameras in active mode, while only the first three steps were performed in passive mode. 


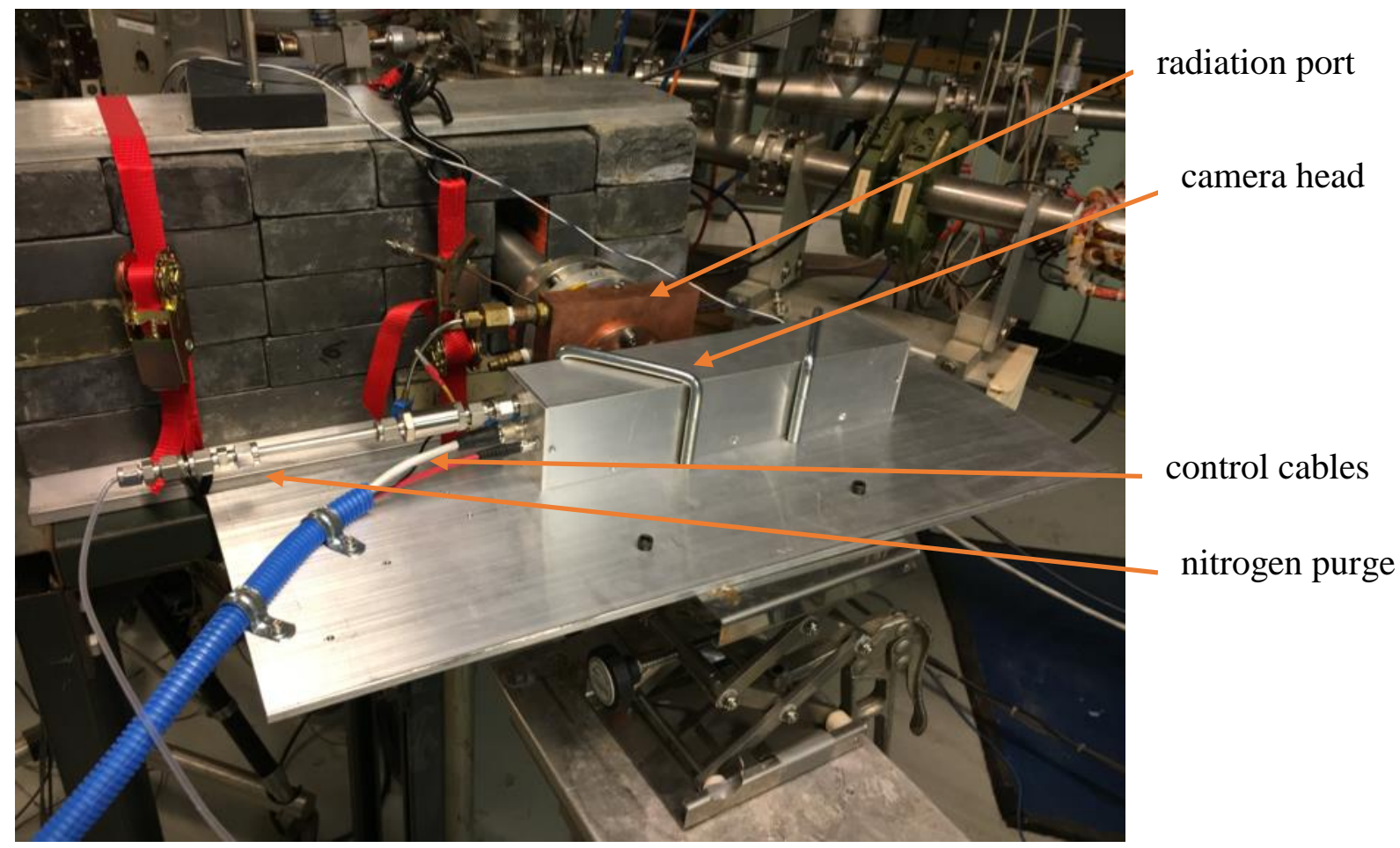

FIGURE 4 Experimental setup, side view. The camera head and video target (a radiationhardened electro-mechanical clock) were placed in an enclosed aluminum box that was fixed in front of the Van de Graaff radiation port. Nitrogen flowed in from the left and electrical connections were made from the left.

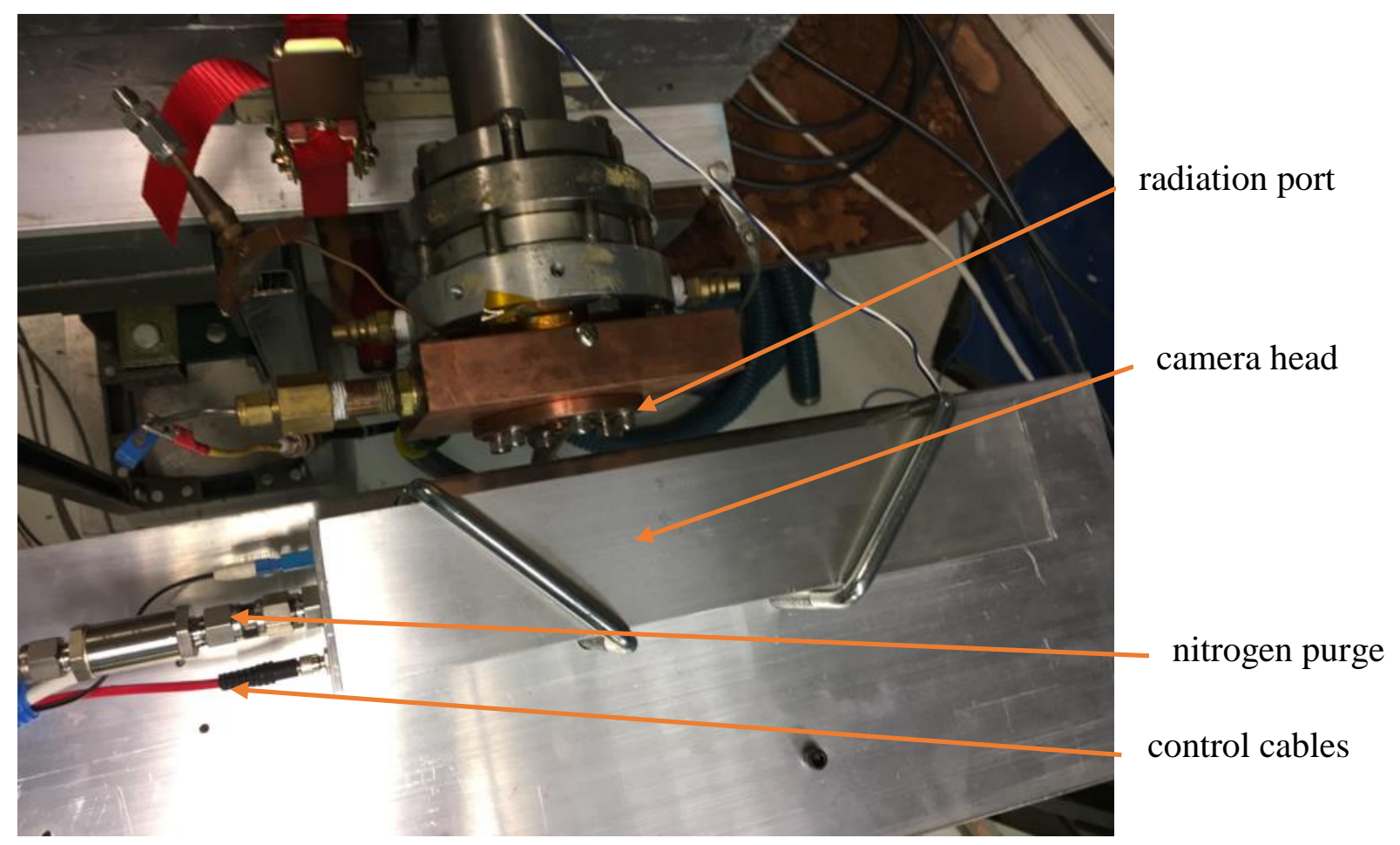

FIGURE 5 Experimental setup, top view. 
The irradiation steps performed were as follows:

1. Data provided by Van de Graaff accelerator personnel were used to determine the position of the camera and electron currents necessary to obtain the desired dose rates. The data contained relevant plots of dose rates at various distances from the $3-\mathrm{MeV}$ photon generation targets, and at different electron currents.

2. The camera heads were positioned on top of a platform in front of the $3-\mathrm{MeV}$ photon target, and secured by C-clamps. A slow flow of nitrogen gas was injected into the camera to flush out the ozone produced.

3. Radiation dose rate levels utilized ranged from $1 \mathrm{kGy} / \mathrm{hr}$ up to a maximum of $10 \mathrm{kGy} / \mathrm{hr}$, at distances of 1 to 3 in. between camera and gamma-ray target. Table 1 shows dose rates vs. electron current, and the interpolation equations obtained from the plots.

4. In active mode, the control equipment used for the camera consisted of a box containing the electronics and a computer system running the control software. The control electronics of the cameras were placed 8 to $10 \mathrm{ft}$ behind the cameras, protected from the radiation by a wall constructed with lead bricks. The computer system was placed in the control room of the Van de Graaff accelerator.

5. Communications between the camera head and the control equipment were transmitted through radiation-hardened cabling.

6. The target used for the vision system in active mode was a 3-in.-diam clock face, placed about 6 in. from the camera. The image of the clock was displayed on the computer monitor and was continuously recorded in video form. The clock contained only its mechanical components, while batteries and electronics were placed away from the radiation region and shielded using lead bricks.

Before the cameras were irradiated in passive mode, they were connected to their control equipment in our laboratory, and images were obtained of photographic targets. This step was repeated after they were returned from the irradiation site. The performance of the camera and the presence of any radiation damage was then estimated by comparing the quality of the images before and after irradiation. In the case of active-mode irradiation, a continuous video of the whole procedure evolution was obtained as part of the procedure. 


\section{RESULTS}

Table 2 shows dose rates, irradiation times, and radiation dose levels for the various cameras irradiated.

TABLE 2 Irradiation times and doses

\begin{tabular}{|c|c|c|c|c|c|}
\hline Date & $\begin{array}{c}\text { Dose Rate } \\
(\mathrm{kGy} / \mathrm{hr})\end{array}$ & $\begin{array}{c}\text { Rad Time } \\
\text { (hours) }\end{array}$ & Source & $\begin{array}{l}\text { Dose } \\
(\mathrm{kGy})\end{array}$ & $\begin{array}{c}\text { Cum Dose } \\
(\mathrm{kGy})\end{array}$ \\
\hline \multicolumn{6}{|c|}{ Camera 2: Passive Mode } \\
\hline Initial & 0.150 & 87 & $\mathrm{Co}^{60}$ (Purdue) & 13 & 13 \\
\hline $1 / 8 / 19$ & 1.087 & 1.0 & Van de Graaff & 1.087 & 14.087 \\
\hline $1 / 29 / 19$ & 1.076 & 4.0 & Van de Graaff & 4.304 & 18.391 \\
\hline $2 / 12 / 19$ & 1.680 & 1.0 & Van de Graaff & 1.680 & 20.071 \\
\hline 3/20/19 & 6.354 & 1.0 & Van de Graaff & 6.354 & 26.425 \\
\hline 3/29/19 & 10.00 & 1.0 & Van de Graaff & 10.00 & 36.425 \\
\hline $4 / 18 / 19$ & 10.00 & 5.0 & Van de Graaff & 50.00 & 86.425 \\
\hline $4 / 24 / 19$ & 10.00 & 6.0 & Van de Graaff & 60.00 & 146.425 \\
\hline \multicolumn{6}{|c|}{ Camera 1: Passive Mode } \\
\hline $1 / 29 / 19$ & 1.076 & 4.0 & Van de Graaff & 4.304 & 4.304 \\
\hline $2 / 12 / 19$ & 1.680 & 1.0 & Van de Graaff & 1.680 & 5.984 \\
\hline 3/20/19 & 5.100 & 1.0 & Van de Graaff & 5.100 & 11.084 \\
\hline 3/29/19 & 10.000 & 1.0 & Van de Graaff & 10.00 & 21.084 \\
\hline $4 / 11 / 19$ & 10.000 & 5.0 & Van de Graaff & 50.00 & 71.084 \\
\hline $4 / 17 / 19$ & 10.000 & 6.0 & Van de Graaff & 60.00 & 131.084 \\
\hline $4 / 23 / 19$ & 10.000 & 6.0 & Van de Graaff & 60.0 & 191.084 \\
\hline $4 / 25 / 19$ & 10.000 & 5.0 & Van de Graaff & 50.0 & 241.084 \\
\hline $4 / 26 / 19$ & 10.000 & 6.0 & Van de Graaff & 60.0 & 301.084 \\
\hline $4 / 29 / 19$ & 10.000 & 5.0 & Van de Graaff & 50.0 & 351.084 \\
\hline $4 / 30 / 19$ & 10.000 & 5.0 & Van de Graaff & 50.0 & 401.084 \\
\hline $5 / 1 / 19$ & 10.000 & 5.0 & Van de Graaff & 50.0 & 451.084 \\
\hline $5 / 8 / 19$ & 10.000 & 5.0 & Van de Graaff & 50.0 & 501.084 \\
\hline $5 / 9 / 19$ & 10.000 & 5.0 & Van de Graaff & 50.0 & 551.084 \\
\hline $5 / 10 / 19$ & 10.000 & 5.0 & Van de Graaff & 50.00 & 601.084 \\
\hline $5 / 14 / 19$ & 10.000 & 5.0 & Van de Graaff & 50.0 & 651.084 \\
\hline $5 / 15 / 19$ & 10.000 & 6.0 & Van de Graaff & 60.0 & 711.084 \\
\hline $5 / 16 / 19$ & 10.000 & 5.0 & Van de Graaff & 50.00 & 761.084 \\
\hline
\end{tabular}


TABLE 2 (Cont.)

\begin{tabular}{|c|c|c|c|c|c|}
\hline Date & $\begin{array}{l}\text { Dose Rate } \\
(\mathrm{kGy} / \mathrm{hr})\end{array}$ & $\begin{array}{l}\text { Rad Time } \\
\text { (hours) }\end{array}$ & Source & $\begin{array}{l}\text { Dose } \\
(\mathrm{kGy})\end{array}$ & $\begin{array}{l}\text { Cum Dose } \\
\text { (kGy) }\end{array}$ \\
\hline \multicolumn{6}{|c|}{ Camera 3: Active Mode } \\
\hline $9 / 3 / 19$ & 1.0 & 0.25 & Van de Graaff & 0.25 & 0.25 \\
\hline $9 / 3 / 19$ & 2.0 & 0.25 & Van de Graaff & 0.50 & 0.75 \\
\hline $9 / 3 / 19$ & 5.0 & 0.25 & Van de Graaff & 1.55 & 2.00 \\
\hline $9 / 3 / 19$ & 7.0 & 0.25 & Van de Graaff & 1.75 & 3.75 \\
\hline 9/3/19 & 10.0 & 0.067 & Van de Graaff & 0.67 & 4.42 \\
\hline $9 / 3 / 19$ & 10.0 & 0.25 & Van de Graaff & 2.5 & 6.92 \\
\hline 9/3/19 & 10.0 & 0.67 & Van de Graaff & 6.7 & 13.62 \\
\hline 9/9/19 & 10.0 & 5.62 & Van de Graaff & 56.2 & 69.82 \\
\hline \multicolumn{6}{|c|}{$\begin{array}{l}\text { Camera 4: Active Mode (Unit } 4 \text { was a modification of unit } 3 \text { with some components } \\
\text { substituted.) }\end{array}$} \\
\hline $12 / 11 / 19$ & 2.0 & 4.0 & Van de Graaff & 8.0 & 8.0 \\
\hline $12 / 11 / 19$ & 5.0 & 3.5 & Van de Graaff & 17.5 & 25.5 \\
\hline $12 / 12 / 19$ & 10.0 & 10.0 & Van de Graaff & 100.0 & 125.5 \\
\hline $12 / 13 / 19$ & 10.0 & 10.0 & Van de Graaff & 100.0 & 225.5 \\
\hline $12 / 16 / 19$ & 10.0 & 10.0 & Van de Graaff & 100.0 & 325.5 \\
\hline $12 / 17 / 19$ & 10.0 & 10.0 & Van de Graaff & 100.0 & 425.5 \\
\hline $12 / 19 / 19$ & 10.0 & 10.0 & Van de Graaff & 100.0 & 525.5 \\
\hline
\end{tabular}

At the time Camera \#1 and Camera \#2 were being assembled, we did not have available all of the necessary rad-hard components, and non-rad-hard components were used in the cameras' manufacture. We expected that this would result in an attenuation of the images. Figures 6 and 7 show test patterns obtained with Camera \#2 before and after the 1.087-kGy irradiation dose, respectively. The brightnesses of the images were measured by comparing pixel values, and the attenuation was estimated to be 0.91 . Similar results were obtained for Camera \#1. Figure 8 shows an image from Camera \#1 after a radiation dose of approximately $6 \mathrm{kGy}$.

Cameras \#3 and \#4, which were tested in active mode, were manufactured with radiationhardened components and did not show this attenuation effect.

One of the key experiments is to determine the effect of radiation on the video image quality, i.e. does the radiation dose rate or total dose degrade or introduce noise into the video image? The noise was calculated from the video of Camera \#3. To compute the noise, a baseline of the image was run without radiation, and noise values could be estimated. A screen shot of the camera software is shown in Figure 9 for a camera head that was not irradiated. A screen shot of the camera software is shown in Figure 10 for a camera head that was irradiated at a rate of $10 \mathrm{kGy} / \mathrm{h}$ and had a total dose of $425 \mathrm{kGy}$. Note that the image shows no observable effects of the radiation. 


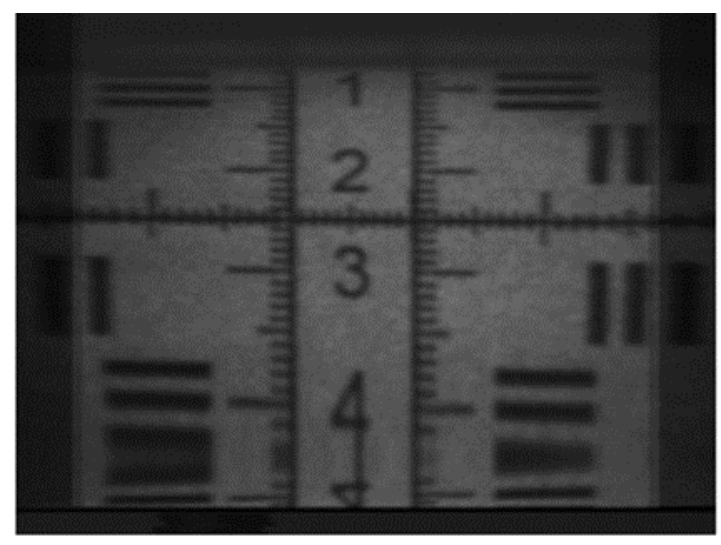

Figure 6 Image from Camera \#2 before irradiation.

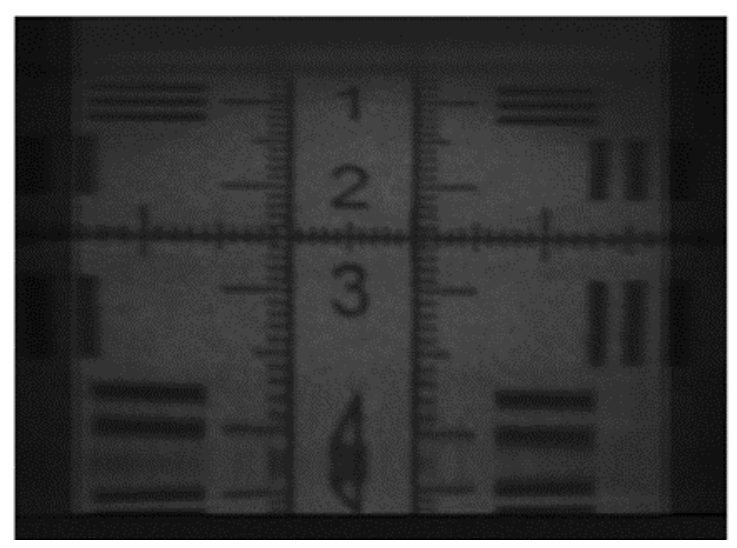

FIGURE 7 Image from Camera \#2 after completion of irradiation testing (760-kGy passive irradiation), exhibiting an attenuation factor of 0.91 .

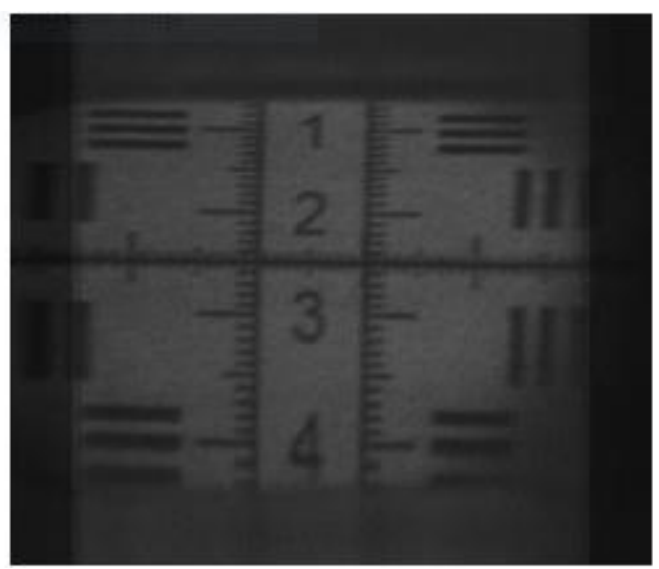

FIGURE 8 Image from Camera \#1 after 5.984-kGy dose. 

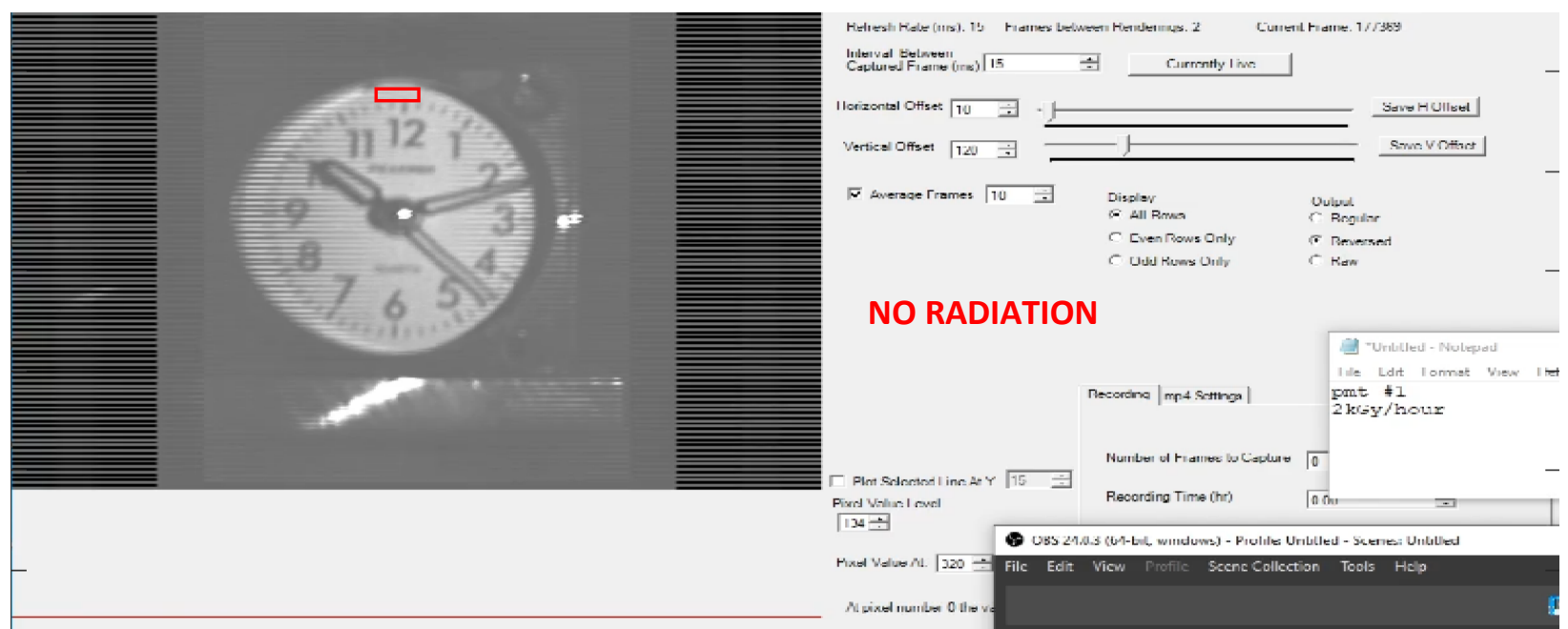

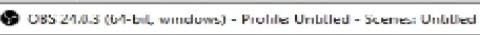
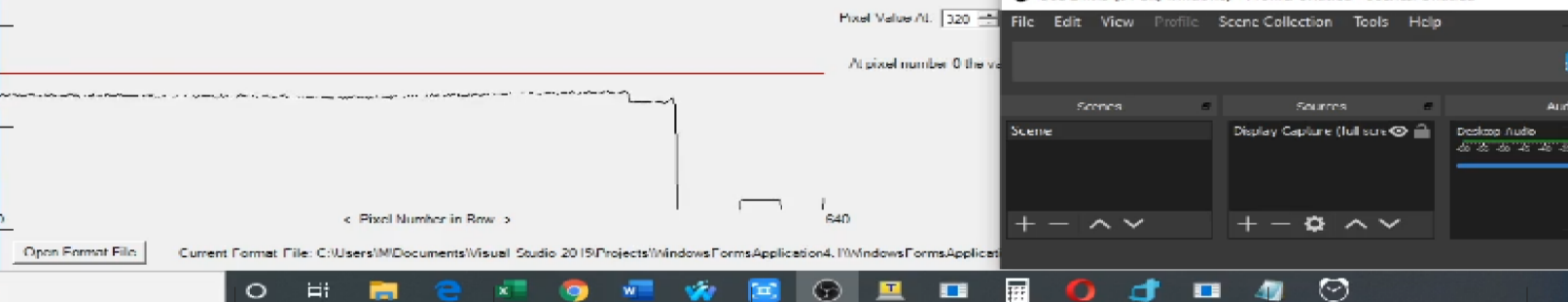

FIGURE 9 Screen shot of the camera control software before irradiation. Below the image in the upper left is a cross section of the intensity across the clock face. The sample area window where the noise calculation was made is shown above the 12 o'clock position. This sample window eliminated the "noise" effects of the moving clock hands.

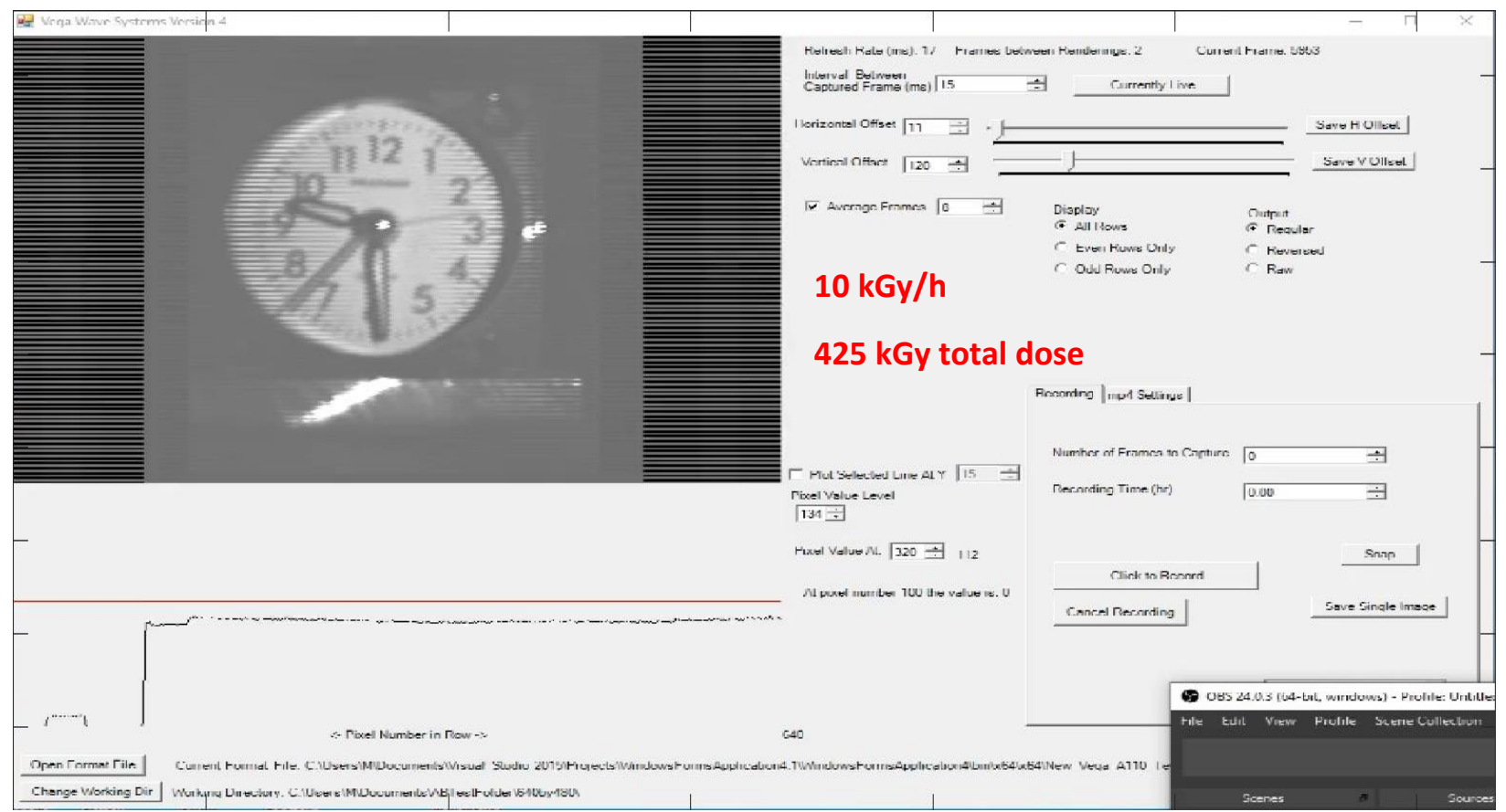

FIGURE 10 Screen shot of the camera control software for camera irradiated at a rate of $10 \mathrm{kGy} / \mathrm{hr}$ with a total dose of $425 \mathrm{kGy}$. Note that the image frame shows no observable effect of the radiation, which is effectively at $10 \mathrm{X}$ the maximum dose rate of a commercial application. 
Screen capture videos were taken of each run of the camera under radiation. Images of each frame extracted from these videos yield a 1920-by-1040 matrix with intensities varying from 0 to 1 . A baseline video of the clock face was taken and a baseline image computed that was an average of all the images in a 15-minute video. That is,

$<$ frame $_{0}>=\frac{1}{N} \sum$ frame

The "noise" was computed for each irradiation run as follows:

noise $=\sqrt{\sum\left(\text { frame }-<\text { frame }_{0}>\right)^{2}}$

The average image $\left\langle\right.$ frame $\left._{0}\right\rangle$ averages out the minute and second hands. The full-frame noise computations overestimate the noise level because the hour, minute and second hands were not removed effectively. To get a more accurate noise measurement, a window section or subsection of the full image frame was used, as shown in Figure 9 (red highlighted box above 12 o'clock), which effectively eliminated the effects of the moving clock hands.

The average intensity level over each frame (gray level) and the average noise over each frame are show in Figure 11. Two sets of averages were taken: one over the clock face and one over a small window outside the sweep of the hands of the clock (see Figure 9). The gray level and the noise level are shown.

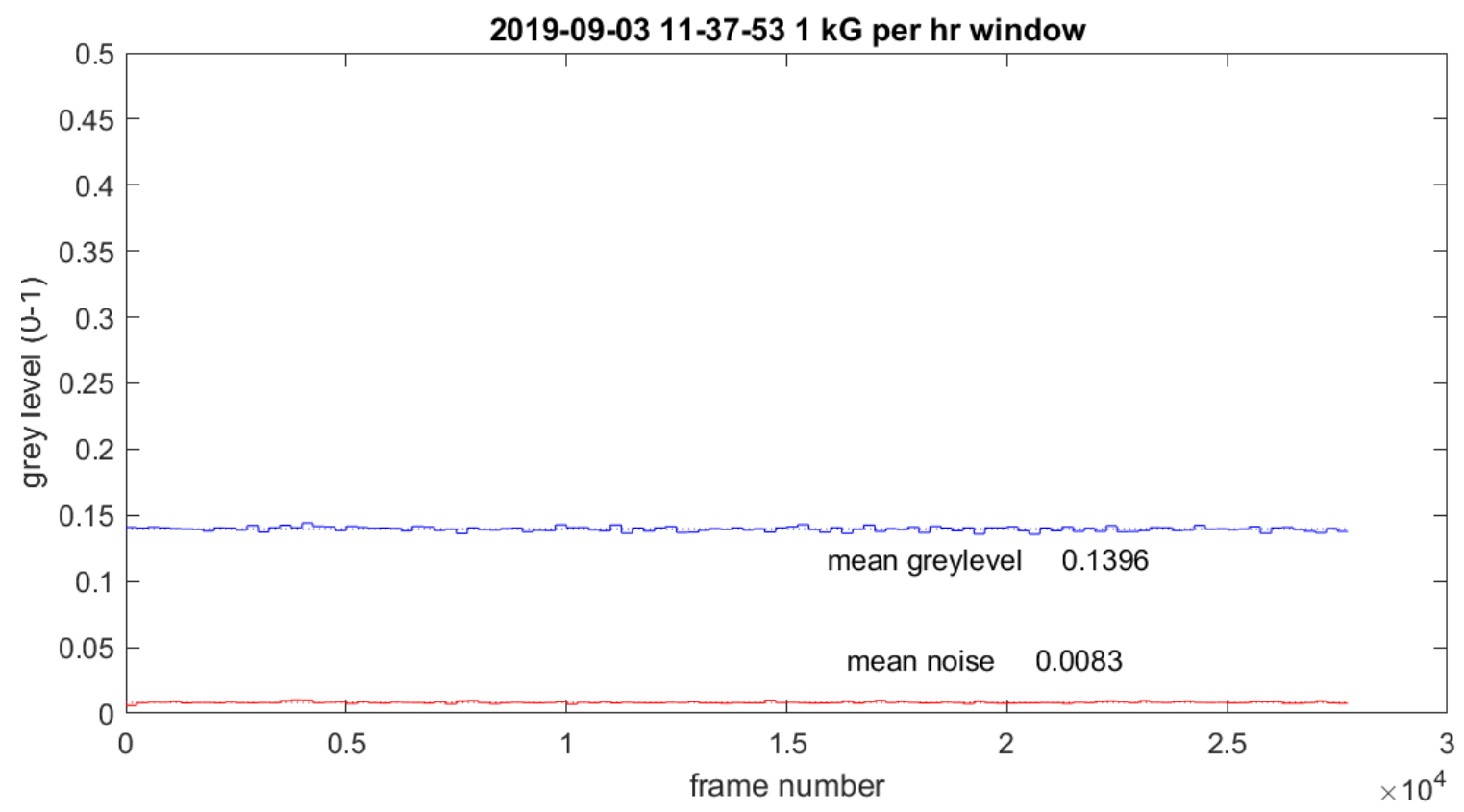

FIGURE 11 The mean gray level and mean noise of the window shown in the clock face for the first 15 minutes of irradiation at $1 \mathrm{kGy} / \mathrm{hr}$. The images are taken at 30 frames per second. 
Table 3, below shows the measured average signal and noise levels for full-frame video and for a selected window in the video data as a function of irradiated dose rate and total dose. The full-frame video data has a moving hour, minute and second hand, which leads to increasing noise level for the full-frame measurement. A subsection window was analyzed which eliminated the moving clock elements and therefore gives a more accurate representation of the video noise.

TABLE 3 Average gray levels and average noise levels for the full image and the window subsample shown in Figure 12 and Figure 13.

\begin{tabular}{ccccccccc}
\hline $\begin{array}{c}\text { Dose rate } \\
(\mathrm{kGy} / \mathrm{h})\end{array}$ & $\begin{array}{c}\text { Full-frame } \\
\text { gray level }\end{array}$ & $\begin{array}{c}\text { Window } \\
\text { gray level }\end{array}$ & $\begin{array}{c}\text { Full-frame } \\
\text { noise }\end{array}$ & $\begin{array}{c}\text { Window } \\
\text { noise }\end{array}$ & $\begin{array}{c}\text { Total } \\
\text { frames }\end{array}$ & $\begin{array}{c}\text { Video } \\
\text { length }\end{array}$ & $\begin{array}{c}\text { Dose } \\
\text { (kGy) }\end{array}$ & $\begin{array}{c}\text { Cum. Dose } \\
\text { (kGy) }\end{array}$ \\
\hline & & & & & & & & \\
0 & 0.4256 & 0.1415 & 0.0213 & 0.0079 & 27725 & 15.40 & 0 & 0 \\
1 & 0.4252 & 0.1396 & 0.0238 & 0.0083 & 27736 & 15.41 & 0.26 & 0.26 \\
2 & 0.4260 & 0.1399 & 0.0243 & 0.0083 & 31671 & 17.60 & 0.59 & 0.84 \\
5 & 0.4254 & 0.1395 & 0.0252 & 0.0087 & 31168 & 17.32 & 1.44 & 2.29 \\
7 & 0.4259 & 0.1392 & 0.0267 & 0.0088 & 28873 & 16.04 & 1.87 & 4.16 \\
10 & 0.4256 & 0.1397 & 0.0270 & 0.0087 & 27980 & 15.54 & 2.59 & 6.75 \\
10 & 0.4393 & 0.1418 & 0.0311 & 0.0087 & 7475 & 4.15 & 0.69 & 7.44 \\
10 & 0.4211 & 0.1413 & 0.0301 & 0.0078 & 110103 & 61.17 & 10.19 & 17.64 \\
10 & 0.4183 & 0.1440 & 0.0374 & 0.0075 & 76863 & 42.70 & 7.12 & 24.75 \\
\hline
\end{tabular}

Figure 12 and Figure 13 visualize the data represented in Table 3: changes in full frame noise and window noise as a function of cumulative dose and dose rate. The full-frame noise rises by $57 \%$ while the window noise remains essentially constant. As discussed above, the full frame noise increase is an artififact because the full frame noise calculation (Eq. 2) does not correctly account for the hour-, minute- and second-hand movements. Therefore, the constant window noise is a more accurate indicator of the noise sensitivity. The fact that it is flat and not increasing with either dose rate or cumulative dose demonstrates that this camera design is essentially immune to the popcorn noise due to radiation hits of the image sensors observed by other camera systems. 


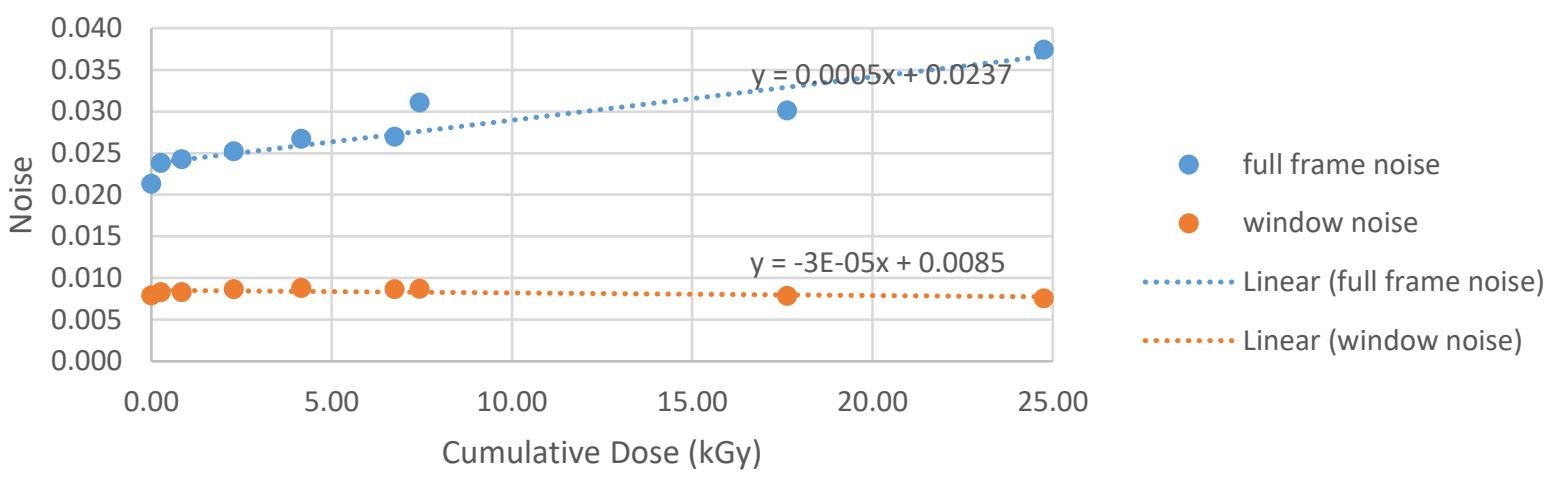

FIGURE 12 Full-frame noise listed in Table 3 as a function of cumulative dose. Note: full-frame noise contains accumulating errors due to the movement of the clock hands, and is therefore less representative of the actual noise than the window noise data.

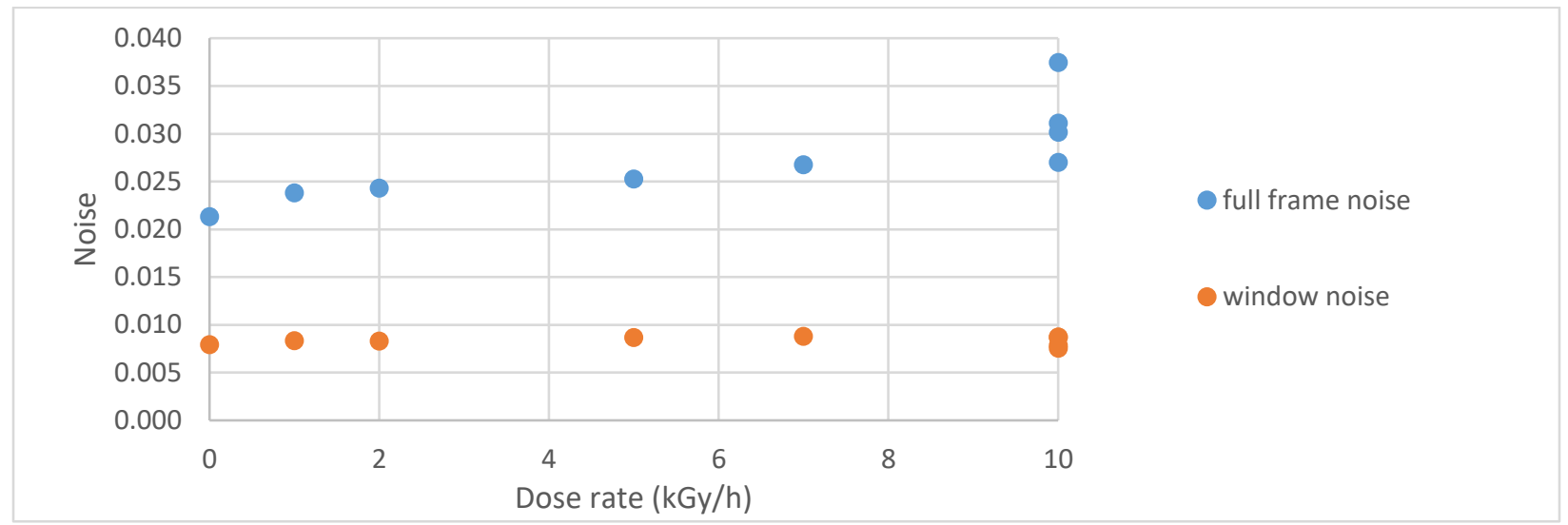

FIGURE 13 Full-frame noise listed in Table 3 as a function of dose rate.

Figure 14 shows an effect observed in images obtained with Camera \#3. The width of the images as recorded with this camera in active mode showed a progressive narrowing. Photographs were taken every 10 min during irradiation and the widths were measured. On a normalized scale, the width changed from an initial value of 1.0 to a value of 0.82 after a $50-\mathrm{kGy}$ dose. 


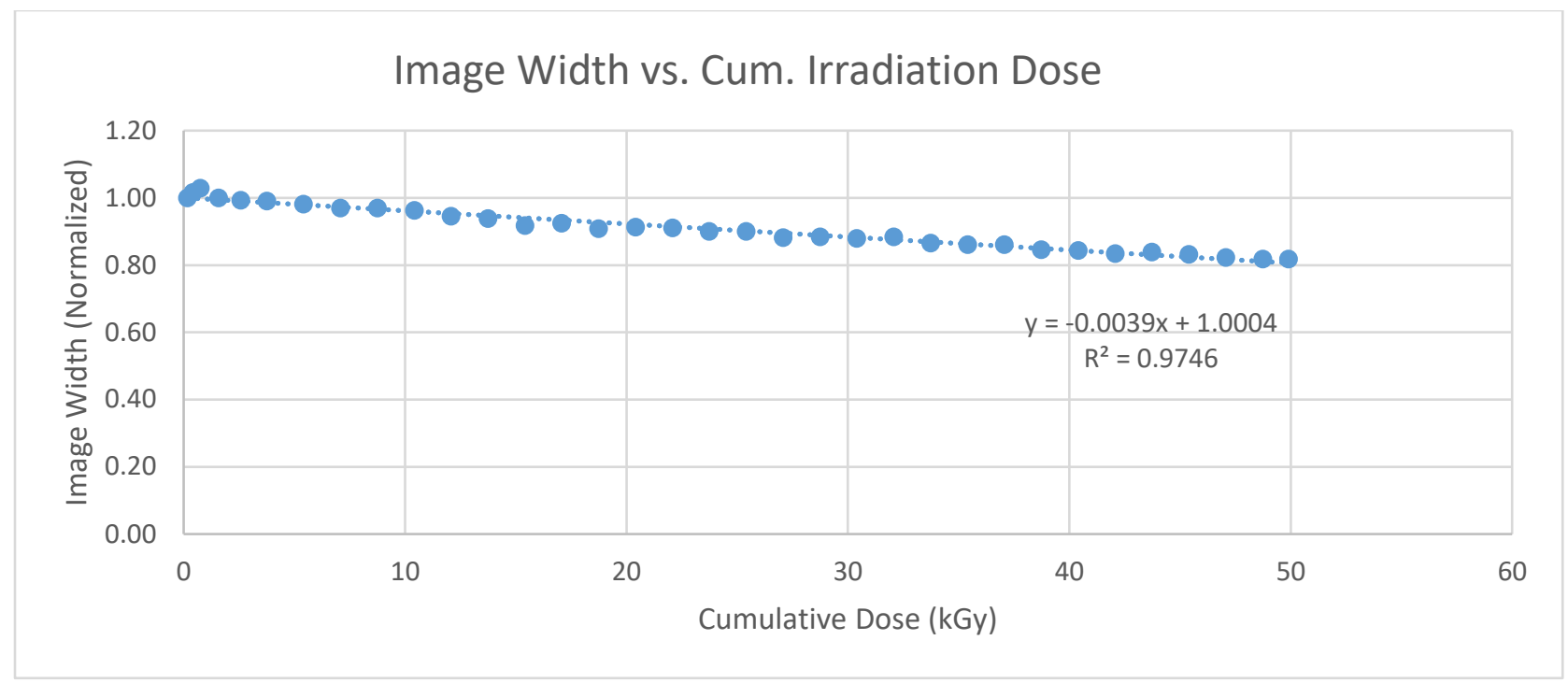

FIGURE 14 Image width vs. cumulative irradiation dose of Camera \#3.

After analysis of the internal camera components, our preliminary analysis attributes this effect to contamination within the camera head due to ionization within the camera. Vega Wave theorized that the ionization of these contaminants by the radiation and the electric fields inside the camera contributed to this effect. Microscope photographs of the components supported this theory. The affected components were replaced in Camera \#4, the contaminants were eliminated or reduced, and the camera was irradiated again. The image-narrowing effect was not detected again, even after a radiation dose in excess of $500 \mathrm{kGy}$ at dose rates of $10 \mathrm{kGy} / \mathrm{hr}$. The frame width was essentially unchanged for Camera \#4 after the components were replaced and the contamination was mitigated, as shown in Figure 15.

To validate these results, we are assembling two more cameras that will be irradiated in the near future.

Camera \#4 was irradiated with a total dose of $525 \mathrm{kGy}$ at dose rates of $10 \mathrm{kGy} / \mathrm{hr}$, with no observable degradation in the video image. 


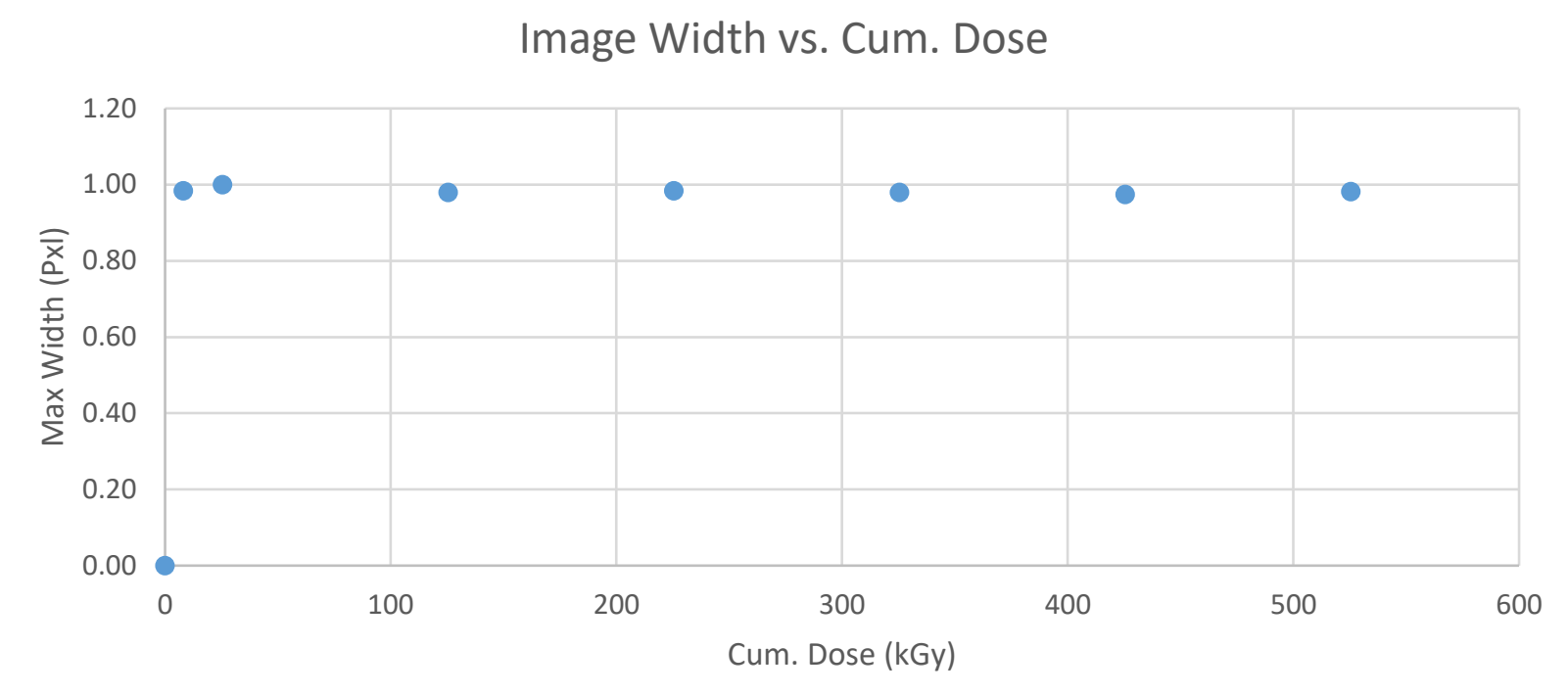

FIGURE 15 Image width for Camera \#4 vs. cumulative irradiation dose. This plot does not show the effect seen in Camera \#3 (Figure 14), and the preliminary attribution of the radiation effect is ionized contaminants, which were eliminated or reduced in Camera \#4.

While the noise data for Camera \#4 has not been completely analysed, the noise measurement (window noise) versus cummulative dose is shown in Figure 16 and the noise (window noise) versus dose rate has been analysed shown in Figure 17. The results show no measureable effect of the image noise with either total accumulated dose, or with dose rate. This confirms the excellent radiation hardness of the Vega Wave design.

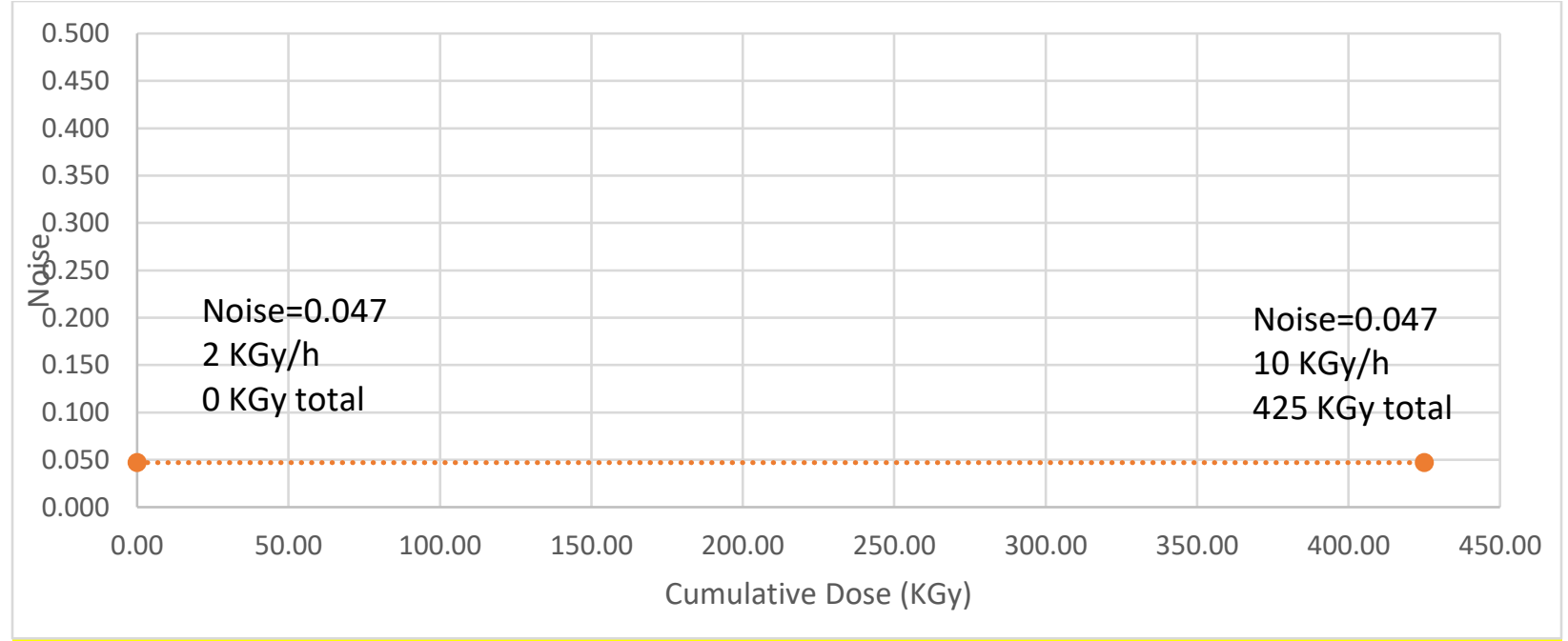

FIGURE 16 Window noise first hour of irradiation at a dose rate $2.0 \mathrm{KGy} / \mathrm{h}$ and first hour 10 $\mathrm{KGy} / \mathrm{h}$ after $425 \mathrm{KGy}$ total dose as a function of total accumulated dose for Camera \#4. 


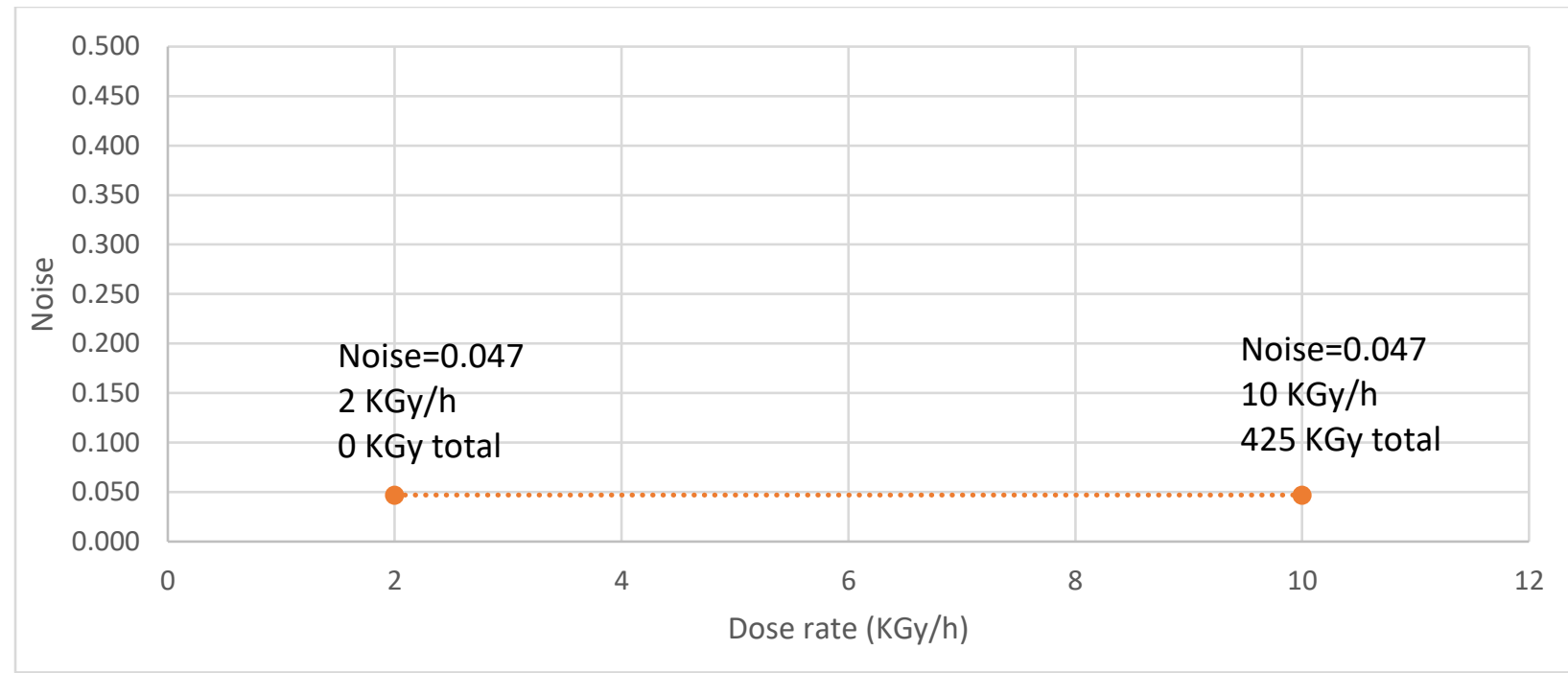

FIGURE 17 Window noise (first hour) of irradiation at a dose rate $2.0 \mathrm{KGy} / \mathrm{h}$ and window noise (first hour) at $10 \mathrm{KGy} / \mathrm{h}$ after $425 \mathrm{KGy}$ total dose as a function of dose rate for Camera \#4. 


\section{CONCLUSION}

The results of the irradiation tests clearly show that the camera exhibited some non-fatal radiation effects from ionized contaminants. Once the contamination was mitigated, the camera showed no effects of radiation at dose rates up to $10 \mathrm{kGy} / \mathrm{hr}$ and total dose rates of $525 \mathrm{kGy}$ (at $10 \mathrm{kGy} / \mathrm{hr}$ ). The results are extremely encouraging, and Vega Wave Systems is planning further irradiations to confirm the radiation hardness of the system up to higher dose rates. Commercial reliability protocols for Mean Time To Failure require testing of 11 to 24 systems. In effect, these results show that the Enduray Vision System developed by Vega Wave Systems is >10X more radiation-hard than the best available commercial competitor in terms of dose rate, and can easily sustain radiation dose rates and total doses seen in the most extreme commercial applications in the nuclear energy industry. 


\section{REFERENCES}

1. S.M. Seltzer and M.J. Berger, "Bremsstrahlung energy spectra from electrons with kinetic energy $1 \mathrm{keV}-10 \mathrm{GeV}$ incident on screened nuclei and orbital electrons of neutral atoms with $Z=1-100$." Atomic Data and Nuclear Tables, Vol. 35, Issue 3, pp. 345-418, November 1986.

2. ANSYS CFX, Release 19.2, 2018. Ansys, Inc., Canonsburg, PA. 



\section{Argonne}

\section{Experimental Operations and Facilities Division}

Argonne National Laboratory

9700 South Cass Avenue, Bldg. 205

Argonne, IL 60439-4832

www.anl.gov 